\title{
PENGARUH APLIKASI BOKASHI TERHADAP DINAMIKA KETERSEDIAAN N, P, DAN S PADA INCEPTISOL KARANGPLOSO, MALANG
}

\section{The Effect of Bokashi Application on Dynamics of N, P, and S Availability in an Inceptisol of Karangploso, Malang}

\author{
Ursulin Sacer Setyastika, Retno Suntari* \\ Jurusan Tanah, Fakultas Pertanian, Universitas Brawijaya \\ *Penulis korespondensi: retnosuntari@ub.ac.id
}

\begin{abstract}
The Inceptisol of Karangploso has low soil $\mathrm{pH}$, low organic matter $(\mathrm{OM})$, medium total soil $\mathrm{N}$, very low $\mathrm{C} / \mathrm{N}$ ratio, and low available sulphur that cause low soil productivity. The application of bokashi preserves strongly productivity and organic matter in the soil. This research aimed to determine the effect of bokashi application in improving soil chemical properties and N, P, Savailable in an Inceptisol of Karangploso. The experiment was conducted in greenhouse of Facultyof Agriculture, Brawijaya University using a completely randomized design with 7 treatments and 3 replications. The treatments consisted of $\mathrm{O}_{1}=$ dose of $5 \mathrm{tha}^{-1}+1 / 2 \mathrm{~A}, \mathrm{O}_{2}=$ dose of $10 \mathrm{tha}^{-1}$ $+1 / 2 \mathrm{~A}, \mathrm{O}_{3}=$ dose of $15 \mathrm{tha}^{-1}+1 / 2 \mathrm{~A}, \mathrm{O}_{4}=$ dose of $20 \mathrm{tha}^{-1}+1 / 2 \mathrm{~A}, \mathrm{O}_{5}=$ dose of $25 \mathrm{tha}^{-1}+1 / 2$ $\mathrm{A}$, and $\mathrm{O}_{6}=$ dose of $30 \mathrm{t} \mathrm{ha}^{-1}+1 / 2 \mathrm{~A}$. The results showed that the increasing dose of bokashi significantly increased soil $\mathrm{pH}$ (from 5.1 to 5.4 ), $\mathrm{C} / \mathrm{N}$ ratio (from 9.64 to 9.93), P-available (from 141 to $142.6 \mathrm{ppm} \mathrm{P}$ ) at $60 \mathrm{DAI}$ (days after incubation), total $\mathrm{N}$ (from 0.21 to $0.24 \%$ at $30 \mathrm{DAI}$ and $0.18 \%$ to $0.24 \%$ at $60 \mathrm{DAI}$ ) and $\mathrm{NO}_{3}$ (from 24.96 to $65.47 \mathrm{ppm}$ at $30 \mathrm{DAI}$ and $14.91 \mathrm{ppm}$ to $39.20 \mathrm{ppm}$ at $60 \mathrm{DAI}$ ) compared to the control, but it had no significantly effect on organic carbon, $\mathrm{OM}, \mathrm{SO}_{4}^{2-}$ in soil. The correlation test showed that there was a strong and positive correlation between $\mathrm{pH}$ and $\mathrm{NO}_{3}{ }^{-}\left(\mathrm{r}=0,77^{*}\right)$, organic carbon and $\mathrm{NO}_{3}^{-}(\mathrm{r}=0,63)$, organic carbon and P-available $\left(\mathrm{r}=0,78^{*}\right), \mathrm{OM}$ to $\mathrm{NO}_{3}{ }^{-}\left(\mathrm{r}=0,70^{*}\right)$, and $\mathrm{OM}$ to P-available $\left(\mathrm{r}=0,86^{*}\right)$.
\end{abstract}

Keywords : availability of N, P, S, bokashi, inceptisol, soil chemical properties

\section{Pendahuluan}

Inceptisol merupakan salah satu ordo tanah yang tersebar luas di Indonesia, yaitu 70,52 juta hektar (ha) atau $37,5 \%$ dari wilayah daratan Indonesia. Inceptisol memiliki nilai yang cukup prospektif untukbudidaya tanaman pertanian dan perkebunan, khususnya pengembangan tanaman pangan (padi, jagung, kacangkacangan) dan hortikultura (sayuran), seperti di Desa Tawangargo, Karangploso, Malangyang menjadi salah satu dari empat kawasan sentra tanaman hortikultura terbesar di Malang Raya. Inceptisol dari Karangploso memiliki $\mathrm{pH}$ tanah masam (5,3), C-organik dan bahan organik (BO) yang rendah $(1,39 \%$ dan $2,41 \%), \mathrm{N}$-total sedang $(0,38 \%), \mathrm{C} / \mathrm{N}$ rasio sangat rendah $(3,66), \mathrm{NO}_{3}$ tinggi $(18,34 \mathrm{ppm}), \quad$-tersedia sangat tinggi (184,08 ppm), dan $\mathrm{SO}_{4}{ }^{2-}$ rendah $(21,57 \mathrm{ppm})$. Pemanfaatan tanah secara intensif/terus menerus untuk budidaya tanaman hortikultura tanpa pengembalian bahan organik menurunkan ketersediaan hara dan kesuburan tanah. Aplikasi BO dibutuhkan untuk memperbaiki sifat kimia Inceptisol yang masam dengan kandungan $\mathrm{BO}$ dan S tersedia rendah. Kaya (2012), menyatakan bahwa Inceptisol memiliki sifat fisik yang baik, tetapi beberapa sifat kimia tidak menguntungkan seperti $\mathrm{pH}$ masam, $\mathrm{BO}$ rendah, dan unsur hara N, P, K yang rendah. 
Upaya perbaikan dengan aplikasi bokashi dari kotoran ternak dan sekam padi diharapkan mampu meningkatkan sifat kimia tanah dan ketersediaan N, P, dan S dalam tanah. Bokashi merupakan bahan-bahan organik yang telah difermentasikan menggunakan decomposer EM4, dan dapat memperbaikitanah yang miskin hara menjadi tanah yang produktif melalui proses alamiah (Kusuma, 2012). Kelebihan bokashi yang digunakan dalam penelitian adalah memiliki $\mathrm{pH} 8$, kadar air 25\%, C-organik $16,20 \%, \mathrm{~N}$-total 1,23\%, P-total $0,53 \%$, K-total $1,72 \%$, S-total $0,26 \%$, dan KTK 76,89 $\mathrm{cmol} / 100$ g. Aplikasi $10 \mathrm{t} / \mathrm{ha}$ bokashi dan 10 t/ha Crotalaria junceanyata meningkatkan BO, KTK, N-total, P-tersedia, dan K (Yuliana, Sumarni, dan Islami, 2015). Aplikasi bokashi sekam padi dapat meningkatkan $\mathrm{pH}, \mathrm{N}$-total, dan Kdalam tanah (Kesumaningwati, 2014 dalam Wijayanto et al., 2016).

Berdasarkan uraian tersebut, penelitian ini bertujuan untuk mengetahui pengaruh bokashi terhadap ketersediaan nitrogen $(\mathrm{N})$, fosfor $(\mathrm{P})$, dan sulfur (S) pada Inceptisol Karangploso, Malang.

\section{Metode Penelitian}

\section{Waktu dan lokasi penelitian}

Penelitian ini dilaksanakan pada bulan Maret hingga Juli 2018 di Rumah Kaca (greenhouse) Jurusan Tanah, Fakultas Pertanian, Universitas Brawijaya. Analisis tanah dan bahan dasar pupuk dilakukan di Laboratorium Kimia Fakultas Pertanian Universitas Brawijaya, dan Laboratorium Balingtan Pati, Jawa Tengah.

\section{Persiapan tanah}

Pengambilan sampel tanah dilakukan di Dusun Leban, Desa Tawangargo, Kecamatan Karangploso, Malang. Tanah diambil pada lapisan olah tanah (kedalaman $0-20 \mathrm{~cm}$ ). Tanah lolos ayakan $2 \mathrm{~mm}$ ditimbang dengan berat tanah $0,93 \mathrm{~kg}$.

\section{Pembuatan bokashi}

Bokashi dibuat berdasarkan Irawan (2012), sebagai berikut:

- Pembuatan $1 \mathrm{t}$ bokashi memerlukan bahan berupa $350 \mathrm{~kg}$ kotoran sapi, $350 \mathrm{~kg}$ kotoran kambing, $300 \mathrm{~kg}$ sekam padi (perbandingan
7:7:6), larutan EM4 dengan perbandingan $1 \mathrm{~L}$ EM4 ke dalam 300 L air;

- Bahan bokashi dicampur dan diaduk merata membentuk gundukan di atas lantai yang kering;

- Larutan EM4 ditambahkan sedikit demi sedikit ke dalam gundukan bahan bokashi, diaduk secara merata hingga air tidak menetes dan bahan tercampur tidak pecah ketika dibentuk/diremas dengan kepalan;

- Bahan yang telah tercampur merata ditutup dengan plastik atau karung goni dan didiamkan selama 7 hari;

- bahan tercampur dibolak-balik ketika suhunya lebih dari $50^{\circ} \mathrm{C}$;

- Bokashi telah terfermentasi dan siap digunakan sebagai pupuk organik bilamana suhu telah mencapai $30^{\circ} \mathrm{C}$ setelah 7 hari.

\section{Rancangan percobaan dan pelaksanaan penelitian}

Percobaan disusun dengan rancangan acak lengkap, tujuh perlakuan dan tiga ulangan. Perlakuan dosis mengacu hasil penelitian dari Amijaya, Pata'dunga, dan Thaha (2015), yang terdiri atas $\mathrm{O}_{0}=$ kontrol (tanpa bokashi), $\mathrm{O}_{1}=$ dosis $5 \mathrm{tha}^{-1}+1 / 2 \mathrm{~A}, \mathrm{O}_{2}=$ dosis $10 \mathrm{tha}^{-1}+1 / 2$ $\mathrm{A}, \mathrm{O}_{3}=\operatorname{dosis} 15 \mathrm{tha}^{-1}+1 / 2 \mathrm{~A}, \mathrm{O}_{4}=\operatorname{dosis} 20 \mathrm{t}$ $\mathrm{ha}^{-1}+1 / 2 \mathrm{~A}, \mathrm{O}_{5}=$ dosis $25 \mathrm{tha}^{-1}+1 / 2 \mathrm{~A}$, dan $\mathrm{O}_{6}=$ dosis $30 \mathrm{tha}^{-1}+1 / 2 \mathrm{~A}$.

Masing-masing perlakuan diberikan tambahan pupuk anorganik sebagai pupuk dasar yang sesuai dengan rekomendasi dari Balitsa (2013), yaitu 250-500 kg ha-1 NPK, 50-100 kg $\mathrm{ha}^{-1}$ SP36, 30-60 kg ha-1 $\mathrm{KCl}, 90-180 \mathrm{~kg} \mathrm{ha}^{-1}$ Urea, 200-400 kg ha-1 ZA, dan dolomit 1-2 t ha-1. Pemupukan anorganik dilakukan pada 7 HSI, dilanjutkan dengan dua kali susulan yaitu pada saat 10-15 HSI, dan 30-35HSI. Penambahan dolomit bertujuan agar unsur hara tetap tersedia dengan dosis $1,60 \mathrm{~g}^{\text {polibag-1. }}{ }^{-1}$. Penyiraman yang diberikan sesuai dengan kondisi kapasitas lapang menggunakan air bebas ion.

\section{Analisis laboratorium}

Analisis dilakukan pada tanah dan bokashi yang diteliti pada 0, 30, dan 60 HSI. Analisis bertujuan untuk mengetahui dinamika $\mathrm{pH}, \mathrm{C}-$ organik, ketersediaan $\mathrm{N}, \mathrm{P}, \mathrm{S}$, dan dilanjutkan perhitungan $\mathrm{BO}$ dan $\mathrm{C} / \mathrm{N}$ rasio pada Inceptisol Karangploso, Malang. 


\section{Analisis Data}

Analisis data menggunakan analysis of variance (anova) berdasarkan metoderancangan acak lengkap (RAL). Apabila diperoleh pengaruh nyata, maka dilanjutkan dengan uji Duncan's Multiple Range Test (DMRT 5\%)untuk mengetahui beda nyata antar perlakuan. Selanjutnya,analisis korelasi digunakan untuk mengetahui hubungan antar sifat kimia tanah ( $\mathrm{pH}, \mathrm{C} / \mathrm{N}, \mathrm{C}$-organik, BO) dengan ketersediaan $\mathrm{N}, \mathrm{P}$, dan $\mathrm{S}$ pada Inceptisol.

\section{Hasil dan Pembahasan}

Analisis dasar terhadap sifat kimia Inceptisol Karangploso, Malang. Inceptisol Karangploso tersaji dalam Tabel 1, Malang memiliki tekstur debu dengan kesuburan dan produktivitas tanah yang rendah. Rendahnya tingkat kesuburan tanah inidisebabkan oleh bahan organik rendah $(1,7 \%-3,5 \%), \mathrm{pH}$ masam $(4,5-5,5)$, dan $\mathrm{SO}_{4}{ }^{2-}$ rendah (20-40 ppm).

Tabel 1. Analisis sifat kimia dasar pada Inceptisol Karangploso, Malang

\begin{tabular}{|c|c|c|}
\hline Parameter Tanah & Nilai & Kriteria*) \\
\hline $\mathrm{pH}\left(\mathrm{H}_{2} \mathrm{O}\right)$ & 5,3 & Masam \\
\hline C-organik $(\%)$ & 1,39 & Rendah \\
\hline $\mathrm{BO}(\%)$ & 2,41 & Rendah \\
\hline $\mathrm{N}(\%)$ & 0,38 & Sedang \\
\hline $\mathrm{C} / \mathrm{N}$ rasio & 3,66 & Sangat rendah \\
\hline $\mathrm{NO}_{3}-(\mathrm{ppm})$ & 18,34 & Tinggi \\
\hline P-tersedia (ppm P) & 91,60 & Sangat tinggi \\
\hline $\mathrm{SO}_{4}^{2-}(\mathrm{ppm})$ & 21,57 & Rendah \\
\hline KTK (cmol $\left.100 \mathrm{~g}^{-1}\right)$ & 28,98 & Tinggi \\
\hline \multicolumn{3}{|l|}{$\begin{array}{l}\text { Kation dapat } \\
\text { ditukar: }\end{array}$} \\
\hline $\mathrm{Ca}\left(\mathrm{me} 100 \mathrm{~g}^{-1}\right)$ & 12,05 & Tinggi \\
\hline $\mathrm{Mg}\left(\operatorname{me} 100 \mathrm{~g}^{-1}\right)$ & 1,94 & Sedang \\
\hline $\mathrm{K}\left(\mathrm{me} 100 \mathrm{~g}^{-1}\right)$ & 1,05 & Sangat tinggi \\
\hline $\mathrm{Na}\left(\mathrm{me} 100 \mathrm{~g}^{-1}\right)$ & 1,23 & Sangat tinggi \\
\hline Kejenuhan Basa (\%) & 56,14 & Sedang \\
\hline \multicolumn{3}{|l|}{ Tekstur: } \\
\hline Pasir (\%) & 5 & \\
\hline Debu $(\%)$ & 85 & Debu \\
\hline Liat (\%) & 10 & \\
\hline
\end{tabular}

*) Kriteria berdasarkanBALITAN (2009)

Muyassir et al.(2012), menyatakan bahwa Inceptisol pada dasarnya memiliki $\mathrm{pH}$ masam
(4,5-6,5), unsur hara essensial $(\mathrm{N}, \mathrm{P}, \mathrm{K})$ rendah, dan tingkat $\mathrm{KB}$ rendah hingga sedang. Rendahnya kandungan bahan organik menyebabkan pentingnya aplikasi bokashi mendukung pertanian keberlanjutan dan efisiensi pupuk anorganik, antara lain dengan memanfaatkan bokashi. Hasil analisis dasar bokashi (Tabel 2) menunjukkan bahwa kandungan hara, C-organik, dan kadar air pada bokashi yang digunakan telah memenuhi kriteria standar baku pupuk organik menurut BALITAN (2009). Bokashi mengandung unsur makro dan mikro yang lengkap, meskipun kandungannya termasuk kriteria rendah. Aplikasi bokashi dapat mendukung perbaikan sifat kimia dan unsur hara dalam tanah (Yuliana et al., 2015; dan Wijayanto et al., 2016).

Tabel 2. Hasil analisis pupuk bokashi

\begin{tabular}{lcc}
\hline $\begin{array}{c}\text { Parameer Pupuk } \\
\text { Bokashi }\end{array}$ & Nilai & Kriteria*) $^{*}$ \\
\hline $\mathrm{pH}\left(\mathrm{H}_{2} \mathrm{O}\right)$ & 8 & $4-8$ \\
$\mathrm{Kadar}$ air $(\%)$ & 25,0 & $15-25$ \\
$\mathrm{C}(\%)$ & 16,20 & $>12$ \\
$\mathrm{~N}(\%)$ & 1,23 & $<6$ \\
$\mathrm{P}_{2} \mathrm{O}_{5}(\%)$ & 0,53 & $<6$ \\
$\mathrm{~K}(\%)$ & 1,72 & $<6$ \\
$\mathrm{C} / \mathrm{N}$ & 13,17 & $15-25$ \\
$\mathrm{KTK}\left(\mathrm{me} 100 \mathrm{~g}^{-1}\right)$ & 76,89 & - \\
$\mathrm{Susunan}$ kation : & & \\
$\mathrm{Ca}(\%)$ & 2,02 & - \\
$\mathrm{Mg}(\%)$ & 0,63 & - \\
$\mathrm{Na}(\%)$ & 5,65 & - \\
$\mathrm{SO}(\%)$ & 0,26 & - \\
\hline${ }^{*} \mathrm{Kriteria}$ berdasarkan BALITAN (2009) & \\
& & \\
pH tanah
\end{tabular}

Aplikasi bokashi tidak berpengaruh nyata terhadap $\mathrm{pH}$ tanah pada 30 HSI, tetapi berpengaruh nyata pada 60 HSI. Nilai pH tanah termasuk ke dalam kriteria masam pada saat 30 dan 60 HSI yang berkisaran 5,1-5,4 (Tabel 3). Tabel 1 menunjukkan bahwa tanah mempunyai kriteria masam, setelah diaplikasikan bokashi pada 30 dan 60 HSI tetap memiliki kriteria masam. Nilai $\mathrm{pH}$ pada perlakuan $\mathrm{O}_{0}$, berbeda nyata dengan perlakuan $\mathrm{O}_{5}+1 / 2 \mathrm{~A}$ dan $\mathrm{O}_{6}+1 / 2$ A (60 HSI). Pemberian bokashi meningkatkan $\mathrm{pH}$ tanah dibandingkan perlakuan tanpa bokashi. Menurut Yuliana et al. (2015), aplikasi pupuk anorganik tanpa atau dengan 
penambahan bahan organik yang rendah akan mengakibatkan $\mathrm{pH}$ tanah menjadi lebih masam, disebabkan oleh penambahan $\mathrm{H}^{+}$dalam tanah dari proses sintesis pupuk anorganik dalam tanah.

Tabel 3. Nilai pH tanah akibat aplikasi bokashi

\begin{tabular}{ccc}
\hline \multirow{2}{*}{ Perlakuan } & \multicolumn{2}{c}{ Rerata $\mathbf{p H}$ Tanah } \\
\cline { 2 - 3 } & $\mathbf{3 0 \text { HSI }}$ & $\mathbf{6 0 ~ H S I}$ \\
\hline $\mathrm{O}_{0}$ & 5,1 & $5,1 \mathrm{a}$ \\
$\mathrm{O}_{1}+1 / 2 \mathrm{~A}$ & 5,3 & $5,3 \mathrm{ab}$ \\
$\mathrm{O}_{2}+1 / 2 \mathrm{~A}$ & 5,2 & $5,1 \mathrm{a}$ \\
$\mathrm{O}_{3}+1 / 2 \mathrm{~A}$ & 5,2 & $5,2 \mathrm{a}$ \\
$\mathrm{O}_{4}+1 / 2 \mathrm{~A}$ & 5,4 & $5,2 \mathrm{a}$ \\
$\mathrm{O}_{5}+1 / 2 \mathrm{~A}$ & 5,3 & $5,4 \mathrm{~b}$ \\
$\mathrm{O}_{6}+1 / 2 \mathrm{~A}$ & 5,3 & $5,4 \mathrm{~b}$ \\
\hline
\end{tabular}

Keterangan: Angka pada kolom yang sama, yang diikuti huruf sama menunjukkan tidak berbeda nyata pada Uji Duncan 5\%. O0 = kontrol (tanpa bokashi), $\mathrm{O} 1+1 / 2 \mathrm{~A}=\operatorname{dosis} 5 \mathrm{t} / \mathrm{ha}, \mathrm{O} 2+1 / 2 \mathrm{~A}=\operatorname{dosis} 10$ $\mathrm{t} / \mathrm{ha}, \mathrm{O} 3+1 / 2 \mathrm{~A}=\operatorname{dosis} 15 \mathrm{t} / \mathrm{ha}, \mathrm{O} 4+1 / 2 \mathrm{~A}=$ dosis $20 \mathrm{t} / \mathrm{ha}, \mathrm{O} 5+1 / 2 \mathrm{~A}=\operatorname{dosis} 25 \mathrm{t} / \mathrm{ha}$, dan O6 $+1 / 2 \mathrm{~A}$ $=$ dosis $30 \mathrm{t} / \mathrm{ha}, 1 / 2 \mathrm{~A}=1 / 2$ dosis pupuk anorganik.

\section{Bahan organik}

Aplikasi bokashi tidak berpengaruh nyata terhadap C-organik dan bahan organic (BO) pada pengamatan 30 HSI dan 60 HSI. Kandungan C-organik dan $\mathrm{BO}$ termasuk ke dalam kriteria rendah pada 30 dan 60 HSI masing-masing yaitu 1,49\%-1,98\% C-organik dan 2,59\%-3,43\% BO (Tabel 4). C-organik dan $\mathrm{BO}$ hasil analisis dasar (Tabel 1) menunjukkan kriteria rendah. Setelah diaplikasikan bokashi pada 30 dan 60 HSI tetap menunjukkan kriteria rendah. C-organik dan $\mathrm{BO}$ dalam tanah tertinggi terdapat pada perlakuan $\mathrm{O}_{6}+1 / 2 \mathrm{~A}(30$ dan 60 HSI). Aplikasi bokashi dapat meningkatkan karbon dalam tanah yang erat kaitannya dengan peningkatan aktivitas mikroorganisme. Peningkatan C-organik setelah aplikasi pupuk organik dapat meningkatkan kesuburan tanah disebabkan terjadinya peningkatan aktivitas mikroorganisme dalam tanah yang menggunakan bahan organik sebagai sumber energi yang dapat mempercepat proses dekomposisi dan reaksi lainnya yang memerlukan bantuan mikroorganisme (Hernandez et al., 2014).
Tabel 4. Pengaruh aplikasi bokashi terhadap kandungan C-organik dan $\mathrm{BO}$ dalam tanah

\begin{tabular}{ccccc}
\hline \multirow{2}{*}{ Perlakuan } & \multicolumn{2}{c}{ C-organik (\%) } & \multicolumn{2}{c}{ BO (\%) } \\
\cline { 2 - 5 } & $\mathbf{3 0}$ & $\mathbf{6 0}$ & $\mathbf{3 0}$ & $\mathbf{6 0}$ \\
& HSI & HSI & HSI & HSI \\
\hline $\mathrm{O}_{0}$ & 1,64 & 1,72 & 2,84 & 2,97 \\
$\mathrm{O}_{1}+1 / 2 \mathrm{~A}$ & 1,62 & 1,49 & 2,81 & 2,59 \\
$\mathrm{O}_{2}+1 / 2 \mathrm{~A}$ & 1,79 & 1,68 & 3,10 & 2,90 \\
$\mathrm{O}_{3}+1 / 2 \mathrm{~A}$ & 1,74 & 1,66 & 3,00 & 2,88 \\
$\mathrm{O}_{4}+1 / 2 \mathrm{~A}$ & 1,95 & 1,81 & 3,38 & 3,13 \\
$\mathrm{O}_{5}+1 / 2 \mathrm{~A}$ & 1,97 & 1,62 & 3,40 & 2,80 \\
$\mathrm{O}_{6}+1 / 2 \mathrm{~A}$ & 1,98 & 1,82 & 3,43 & 3,15 \\
\hline
\end{tabular}

Keterangan: Angka pada kolom yang sama, yang diikuti huruf sama menunjukkan tidak berbeda nyata pada Uji Duncan 5\%.

\section{C/N rasio}

Aplikasi bokashi tidak berpengaruh nyata terhadap $\mathrm{C} / \mathrm{N}$ pada 60 HSI. C/N rasio termasuk dalam kriteria rendah yaitu berkisaran 7,40-9,93 (Tabel 5). C/N rasio tanah hasil analisis dasar (Tabel 1) menunjukkan kriteria sangat rendah. Setelah aplikasi bokashi pada 30 dan 60 HSI mengalami peningkatan dari kriteria sangat rendah menjadi rendah. Perlakuan $\mathrm{O}_{2}+$ $1 / 2$ A (30 HSI) dan $\mathrm{O}_{4}+1 / 2 \mathrm{~A}(60 \mathrm{HSI})$ memberikan nilai $\mathrm{C} / \mathrm{N}$ rasio tertinggi yaitu 8,98 dan 9,93. Rendahnya $\mathrm{C} / \mathrm{N}$ rasio bokashi (kurang dari kisaran 15-25) yang digunakan dalam penelitian menyebabkan $\mathrm{C} / \mathrm{N}$ rasio dalam tanah setelah diaplikasikan bokashi juga masih memiliki kriteria rendah.

Tabel 5. C/N rasio tanah akibat aplikasi bokashi

\begin{tabular}{ccc}
\hline \multirow{2}{*}{ Perlakuan } & \multicolumn{2}{c}{ Rerata C/N Rasio } \\
\cline { 2 - 3 } & 30 HSI & 60 HSI \\
\hline $\mathrm{O}_{0}$ & 7,82 & $9,64 \mathrm{~b}$ \\
$\mathrm{O}_{1}+1 / 2 \mathrm{~A}$ & 7,87 & $7,70 \mathrm{a}$ \\
$\mathrm{O}_{2}+1 / 2 \mathrm{~A}$ & 8,98 & $8,78 \mathrm{ab}$ \\
$\mathrm{O}_{3}+1 / 2 \mathrm{~A}$ & 7,95 & $8,40 \mathrm{ab}$ \\
$\mathrm{O}_{4}+1 / 2 \mathrm{~A}$ & 8,87 & $9,93 \mathrm{~b}$ \\
$\mathrm{O}_{5}+1 / 2 \mathrm{~A}$ & 8,24 & $7,40 \mathrm{ab}$ \\
$\mathrm{O}_{6}+1 / 2 \mathrm{~A}$ & 8,16 & $8,79 \mathrm{ab}$ \\
\hline
\end{tabular}

Keterangan: Angka pada kolom yang sama, yang diikuti huruf sama menunjukkan tidak berbeda nyata pada Uji Duncan 5\%. 


\section{N-total tanah}

Aplikasi bokashi berpengaruh nyata terhadap N-total tanah pada 30 HSI dan 60 HSI.N-total termasuk kriteria rendah hingga sedang pada 30 dan 60 HSI yaitu dalam kisaran $0,18 \%-0,24 \%$ (Tabel 6). N-total pada perlakuan O0 berbeda nyata dengan perlakuan $\mathrm{O} 5+1 / 2 \mathrm{~A}, \mathrm{O} 6+1 / 2 \mathrm{~A}$ pada 30 dan $60 \mathrm{HSI}$. N-total tertinggi terdapat pada perlakuan $\mathrm{O}_{6}+1 / 2 \mathrm{~A}(30 \mathrm{HSI})$ dan $\mathrm{O}_{5}+1 / 2$ A (60 HSI).Dibandingkan dengan perlakuan kontrol, perlakuan bokashi mampu meningkatkan N-total dalam tanah. Hal ini disebabkan bokashi yang diteliti memiliki konsentrasi $\mathrm{C}$ dan $\mathrm{N}$ sebesar 16,24\% dan 1,23\% yang lebih tinggi dibandingkan bokashi yang diteliti oleh Suriadikarta dan Setyorini (2006), Velasco et al. (2014), dan Solis et al. (2016).

Tabel 6. Pengaruh aplikasi bokashi terhadap Ntotal pada 30 dan 60 HSI

\begin{tabular}{ccc}
\hline \multirow{2}{*}{ Perlakuan } & \multicolumn{2}{c}{ Rerata $\mathbf{N}$-total (\%) } \\
\cline { 2 - 3 } & $\mathbf{3 0} \mathbf{H S I}$ & $\mathbf{6 0 ~ H S I}$ \\
\hline $\mathrm{O}_{0}$ & $0,21 \mathrm{a}$ & $0,18 \mathrm{a}$ \\
$\mathrm{O}_{1}+1 / 2 \mathrm{~A}$ & $0,21 \mathrm{a}$ & $0,20 \mathrm{abc}$ \\
$\mathrm{O}_{2}+1 / 2 \mathrm{~A}$ & $0,20 \mathrm{a}$ & $0,19 \mathrm{ab}$ \\
$\mathrm{O}_{3}+1 / 2 \mathrm{~A}$ & $0,22 \mathrm{ab}$ & $0,20 \mathrm{abc}$ \\
$\mathrm{O}_{4}+1 / 2 \mathrm{~A}$ & $0,22 \mathrm{ab}$ & $0,18 \mathrm{ab}$ \\
$\mathrm{O}_{5}+1 / 2 \mathrm{~A}$ & $0,24 \mathrm{bc}$ & $0,22 \mathrm{c}$ \\
$\mathrm{O}_{6}+1 / 2 \mathrm{~A}$ & $0,24 \mathrm{c}$ & $0,21 \mathrm{bc}$ \\
\hline
\end{tabular}

Keterangan: Angka pada kolom yang sama, yang diikuti huruf sama menunjukkan tidak berbeda nyata pada Uji Duncan 5\%.

\section{Nitrat $\left(\mathrm{NO}_{3}{ }^{-}\right)$}

Aplikasi bokashi berpengaruh nyata terhadap nilai $\mathrm{NO}_{3}$ - pada 30 dan $60 \mathrm{HSI} . \mathrm{NO}_{3}{ }^{-}$termasuk kriteria tinggi hingga sangat tinggi pada 30 dan 60 HSI yaitu dalam kisaran 14,91-65,47 ppm (Tabel 7). Rerata $\mathrm{NO}_{3}$ tertinggi terdapat pada perlakuan $\mathrm{O}_{4}+1 / 2 \mathrm{~A}(65,47 \mathrm{ppm})$ pada $30 \mathrm{HSI}$ dan $\mathrm{O}_{5}+1 / 2 \mathrm{~A}(39,20 \mathrm{ppm})$ pada $60 \mathrm{HSI}$. Perlakuan $\mathrm{O}_{0}$ berbeda nyata dengan perlakuan $\mathrm{O}_{4}+1 / 2$ A dan $\mathrm{O}_{5}+1 / 2$ A (30 HSI). Sedangkan pada $60 \mathrm{HSI}, \mathrm{O}_{0}$ berbeda nyata dengan $\mathrm{O}_{3}+1 / 2$ A dan $\mathrm{O}_{5}+1 / 2$ A. Sebanding dengan penelitian Boechat et al. (2013), menyatakan bahwa aplikasi fermentasi kompos bokashi secara nyata mempercepat proses mineralisasi nitrogen dengan peningkatan mencapai 54\% dibandingkan kontrol pada 7-90 HSI. Dengan demikian, proses mineralisasi nitrogen dalam tanah akan meningkat dengan penambahan bokashi dalam tanah.

Tabel 7. Pengaruh aplikasi bokashi terhadap $\mathrm{NO}_{3}$ - pada 30 dan $60 \mathrm{HSI}$

\begin{tabular}{ccc}
\hline \multirow{2}{*}{ Perlakuan } & \multicolumn{2}{c}{\left.${\text { Rerata } \mathbf{~ N O}_{3}}^{-} \mathbf{( p p m}\right)$} \\
\cline { 2 - 3 } & $\mathbf{3 0} \mathbf{H S I}$ & $\mathbf{6 0} \mathbf{H S I}$ \\
\hline $\mathrm{O}_{0}$ & $24,96 \mathrm{a}$ & $14,91 \mathrm{a}$ \\
$\mathrm{O}_{1}+1 / 2 \mathrm{~A}$ & $36,70 \mathrm{ab}$ & $24,61 \mathrm{abc}$ \\
$\mathrm{O}_{2}+1 / 2 \mathrm{~A}$ & $28,73 \mathrm{a}$ & $27,99 \mathrm{abc}$ \\
$\mathrm{O}_{3}+1 / 2 \mathrm{~A}$ & $37,55 \mathrm{ab}$ & $36,69 \mathrm{bc}$ \\
$\mathrm{O}_{4}+1 / 2 \mathrm{~A}$ & $65,47 \mathrm{c}$ & $26,29 \mathrm{abc}$ \\
$\mathrm{O}_{5}+1 / 2 \mathrm{~A}$ & $50,73 \mathrm{bc}$ & $39,20 \mathrm{c}$ \\
$\mathrm{O}_{6}+1 / 2 \mathrm{~A}$ & $35,48 \mathrm{ab}$ & $22,54 \mathrm{ab}$ \\
\hline
\end{tabular}

Keterangan: Angka pada kolom yang sama, yang diikuti huruf sama menunjukkan tidak berbeda nyata pada Uji Duncan 5\%.

Gambar 1. menunjukkan bahwa semua perlakuan dosis bokashi meningkatkan nilai $\mathrm{NO}_{3}$ pada $30 \mathrm{HSI}$, dan menurun pada 60 HSI.

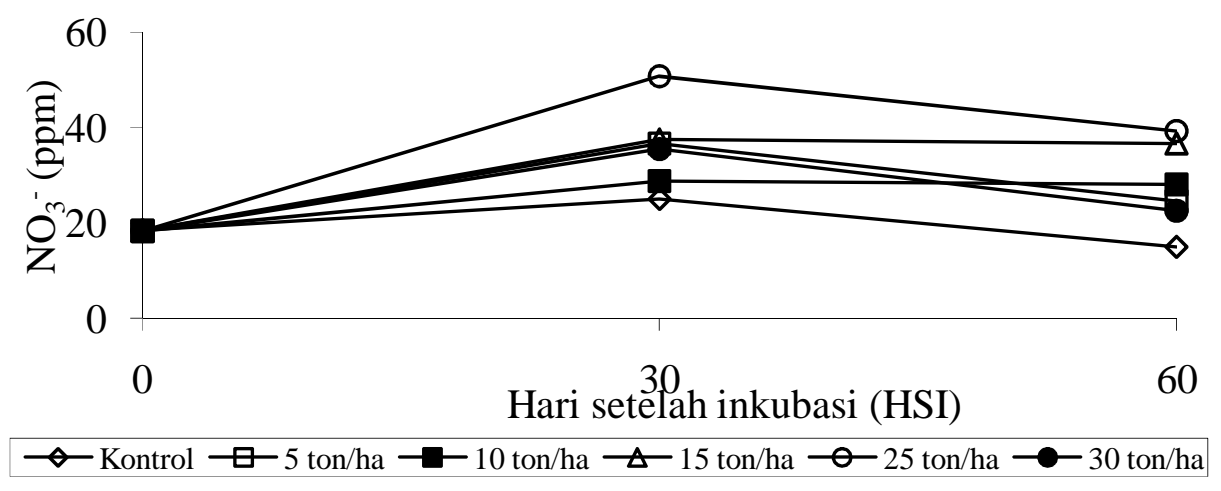

Gambar 1. Dinamika $\mathrm{NO}_{3}$ pada berbagai perlakuan dosis bokashi 
Penurunan $\mathrm{NO}_{3}-$ ini disebabkan penurunan aktivitas bakteri. Bakteri nitrifikasi (Nitrosomonas dan Nitrobacter) bekerja optimum pada $\mathrm{pH} 7-8$ sehingga terjadi proses oksidasi lengkap dari amonia menjadi nitrat (Bhaskar dan Chryulu, 2005; dan Gee, et al., 2014).

\section{P-tersedia}

Aplikasi bokashi tidak berpengaruh nyata terhadap P-tersedia pada 30 HSI tetapi berpengaruh nyata pada 60 HSI. Nilai P-tersedia dalam tanah termasuk kriteria sangat tinggi dengan kisaran 120,5-168,1 ppm P (Tabel 8).

Tabel 8. Pengaruh aplikasi bokashi terhadap Ptersedia pada 30 dan 60 HSI

\begin{tabular}{ccc}
\hline \multirow{2}{*}{ Perlakuan } & \multicolumn{2}{c}{$\begin{array}{c}\text { Rerata P-tersedia } \\
\text { tanah }\end{array}$} \\
\cline { 2 - 3 } & $\mathbf{3 0 \text { HSI }}$ & $\mathbf{6 0 ~ H S I}$ \\
\hline $\mathrm{O}_{0}$ & 144,3 & $141 \mathrm{c}$ \\
$\mathrm{O}_{1}+1 / 2 \mathrm{~A}$ & 145,5 & $142,6 \mathrm{c}$ \\
$\mathrm{O}_{2}+1 / 2 \mathrm{~A}$ & 143,6 & $120,5 \mathrm{a}$ \\
$\mathrm{O}_{3}+1 / 2 \mathrm{~A}$ & 153,0 & $121,4 \mathrm{a}$ \\
$\mathrm{O}_{4}+1 / 2 \mathrm{~A}$ & 150,9 & $125,9 \mathrm{ab}$ \\
$\mathrm{O}_{5}+1 / 2 \mathrm{~A}$ & 166,5 & $132,2 \mathrm{bc}$ \\
$\mathrm{O}_{6}+1 / 2 \mathrm{~A}$ & 168,1 & $128,2 \mathrm{ab}$ \\
\hline
\end{tabular}

Keterangan: Angka pada kolom yang sama, yang diikuti huruf sama menunjukkan tidak berbeda nyata pada Uji Duncan 5\%.
P-tersedia dalam hasil analisis dasar (Tabel 1) menunjukkan kriteria sangat tinggi. Setelah aplikasi bokashi pada 30 dan 60 HSI tetap menunjukkan kriteria sangat tinggi. Rerata Ptersedia tertinggi terdapat pada perlakuan $\mathrm{O}_{6}+$ $1 / 2$ A (30 HSI) dan $\mathrm{O}_{1}+1 / 2$ A (60 HSI). Perlakuan $\mathrm{O}_{0}$ berbeda nyata dengan perlakuan $\mathrm{O}_{2}+1 / 2 \mathrm{~A}, \mathrm{O}_{3}+1 / 2 \mathrm{~A}, \mathrm{O}_{4}+1 / 2 \mathrm{~A}$, dan $\mathrm{O}_{6}+1 / 2$ A. Pupuk organik meningkatkan ketersediaan $\mathrm{P}$ disebabkan sebagai komponen organik akan melepaskan $\mathrm{CO}_{2}$ dan konsentrasi $\mathrm{CO}_{2}$ yang lebih tinggi, dan akan meningkatkan prosesdekomposisi mineral fosfat sehingga ketersediaan $\mathrm{P}$ dalam tanah akan meningkat pula (Hernadez et al., 2014).

Gambar 2. menunjukkan bahwa semua perlakuan dosis bokashi meningkatkan ketersediaan P pada 30 HSI, dan menurun pada 60 HSI. Hal ini disebabkan aplikasi bokashi mendorong pelepasan $\mathrm{P}$ yang terfiksasi oleh $\mathrm{Al}$ dan $\mathrm{Fe}$ pada tanah masam, sehingga meningkatkan $\mathrm{P}$ tersedia dalam laarutan tanah. Pengaruh bahan organik terhadap ketersediaan $\mathrm{P}$ dapat secara langsung melalui proses mineralisasi atau secara tidak langsung melalui pelepasan $\mathrm{P}$ yang terfiksasi. Hasil dekomposisi bahan organik berupa asam-asam organik membentuk ikatan khelasi dengan ion $\mathrm{Al}$ dan $\mathrm{Fe}$, sehingga menurunkan kelarutan ion $\mathrm{Al}$ dan Fe.

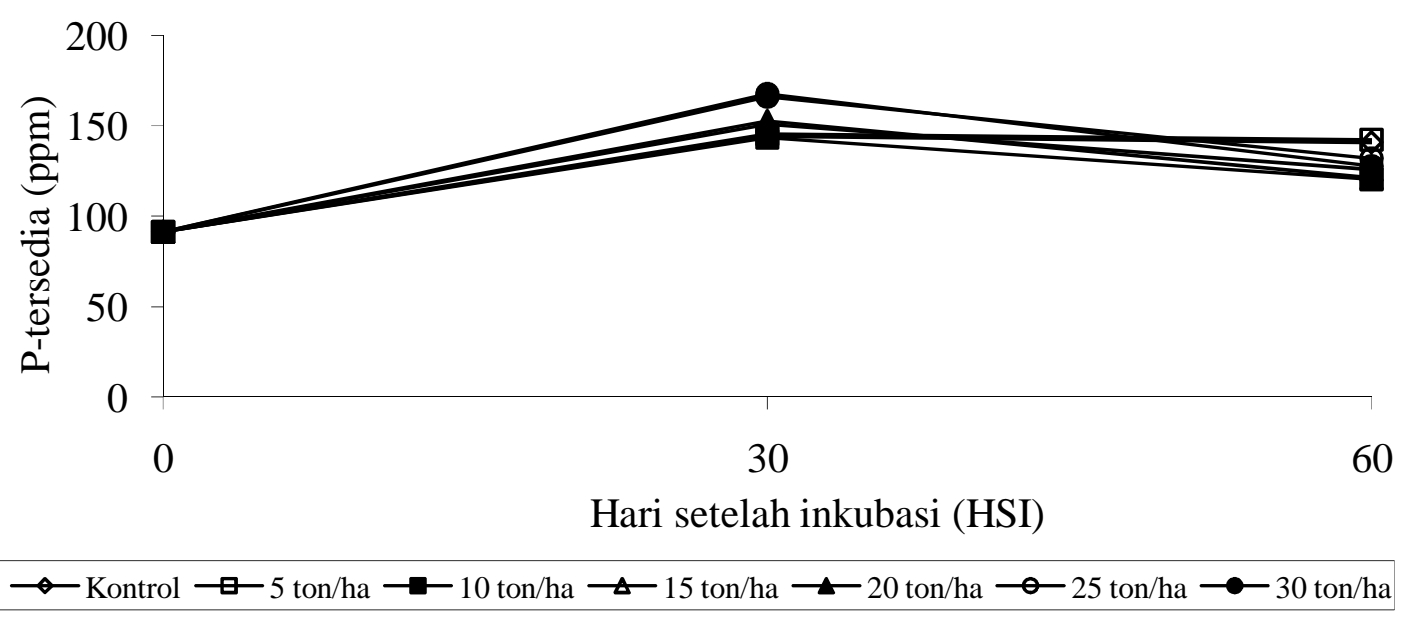

Gambar 2. Dinamika P-tersedia pada berbagai perlakuan dosis bokasi. 
Asam-asam organik melepaskan P yang terjerap dan meningkatkan ketersediaan $\mathrm{P}$ larutan tanah (Sari et al., 2017).

\section{Sulfat $\left(\mathrm{SO}_{4}{ }^{-}\right)$}

Aplikasi bokashi tidak berpengaruh nyata terhadap $\mathrm{SO}_{4}^{2-}$ pada 30 dan $60 \mathrm{HSI}$. Nilai $\mathrm{SO}_{4}{ }^{2-}$ pada 30 dan 60 HSI termasuk kriteria rendah hingga sedang demgan kisaran 66,99-172,5 ppm (Tabel 9).

Tabel 9. Pengaruh aplikasi bokashi terhadap $\mathrm{SO}_{4}{ }^{2-}$ pada 30 dan $60 \mathrm{HSI}$

\begin{tabular}{ccc}
\hline \multirow{2}{*}{ Perlakuan } & \multicolumn{2}{c}{ Rerata SO $_{4}{ }^{2-}$ Tanah $(\mathbf{p p m})$} \\
\cline { 2 - 3 } & 30 HSI & $\mathbf{6 0 ~ H S I}$ \\
\hline $\mathrm{O}_{0}$ & 178,7 & 67,52 \\
$\mathrm{O}_{1}+1 / 2 \mathrm{~A}$ & 158,1 & 66,99 \\
$\mathrm{O}_{2}+1 / 2 \mathrm{~A}$ & 171,1 & 72,63 \\
$\mathrm{O}_{3}+1 / 2 \mathrm{~A}$ & 172,5 & 94,44 \\
$\mathrm{O}_{4}+1 / 2 \mathrm{~A}$ & 159,5 & 79,58 \\
$\mathrm{O}_{5}+1 / 2 \mathrm{~A}$ & 152,1 & 103,19 \\
$\mathrm{O}_{6}+1 / 2 \mathrm{~A}$ & 167,7 & 71,36 \\
\hline
\end{tabular}

Keterangan: Angka pada kolom yang sama, yang diikuti huruf sama menunjukkan tidak berbeda nyata pada Uji Duncan 5\%.
Nilai $\mathrm{SO}_{4}^{2-}$ hasil analisis dasar (Tabel 1) menunjukkan kriteria rendah. Setelah diaplikasikan bokashi pada pengamatan 30 HSI menunjukkan peningkatan dari rendah menjadi sedang. Nilai $\mathrm{SO}_{4}{ }^{2-}$ dalam tanah tertinggi terdapat pada perlakuan $\mathrm{O}_{0}(30 \mathrm{HSI})$ dan $\mathrm{O}_{5}+$ $1 / 2$ A (60 HSI). Kondisi tanah yang aerob (tidak tergenang) dan masam dapat mendorong pembentukan ion $\mathrm{SO}_{4}^{2-l e b i h}$ cepat melalui proses mineralisasi senyawa belerang organik yang akan membebaskan $\mathrm{H}_{2} \mathrm{~S}$ dan teroksidasi menjadi $\mathrm{SO}_{4}{ }^{2-}$ oleh bakteri belerang khemotrof (Beggiatoa thiothrix) atau mikroorganisme dari genus Thiobacillus (Sari et al., 2017). Adanya kemungkinan faktor ini ditunjukkan pada nilai $\mathrm{SO}_{4}^{2-}$ perlakuan $\mathrm{O}_{0}(30 \mathrm{HSI})$ yang memiliki nilai $\mathrm{SO}_{4}{ }^{2-}$ lebih tinggi dibandingkan perlakuan lain.

Gambar 3. menunjukkan bahwa semua perlakuan dosis bokashi meningkat pada 30 HSI, kemudian $\mathrm{SO}_{4}{ }^{2-}$ menurun pada $60 \mathrm{HSI}$. Peningkatan yang terjadi disebabkan adanya penambahan bokashi dengan kandungan $\mathrm{SO}_{4}{ }^{2-}$ $(0,26 \%)$ yang diaplikasikan ke tanah. Selain itu, penambahan pupuk ZA yang memiliki 24\% kadar $\mathrm{S}$ dalam bentuk $\mathrm{SO}_{4}{ }^{2-}$.

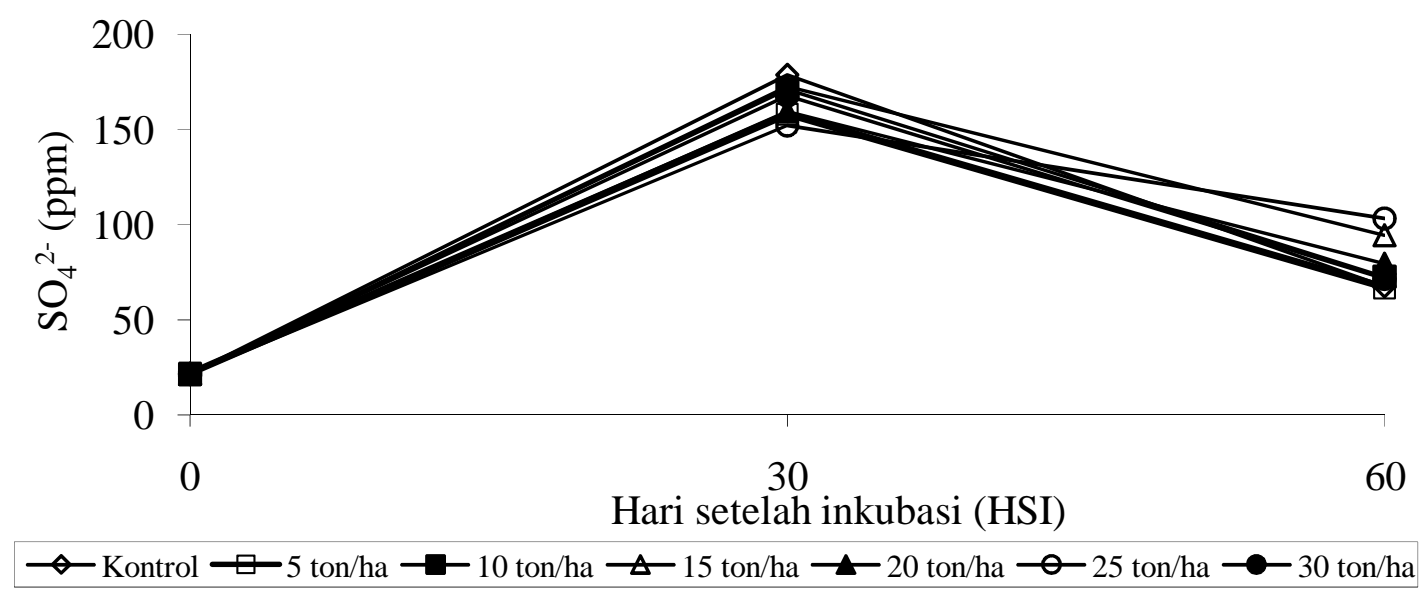

Gambar 3. Dinamika $\mathrm{SO}_{4}^{2}$-pada berbagai perlakuan dosis bokashi.

\section{Hubungan sifat kimia tanah dengan ketersediaan $\boldsymbol{N}, \boldsymbol{P}$, dan $\boldsymbol{S}$}

Hasil korelasi menunjukkan adanya hubungan atau korelasi antara sifat kimia tanah $(\mathrm{pH}, \mathrm{C}-$ organik, $\mathrm{BO}$ ) dengan $\mathrm{NO}_{3}{ }^{-}$, P-tersedia, dan $\mathrm{SO}_{4}{ }^{2-}$. Nilai $\mathrm{pH}$ tanah memiliki korelasi kuat dan positif dengan $\mathrm{NO}_{3}{ }^{-}\left(\mathrm{r}=0,77^{*}\right)$ pada pengamatan
30 HSI. Sedangkan pada pengamatan 60 HSI, nilai $\mathrm{pH}$ berkorelasi sangat kuat dan positif dengan $\mathrm{N}$-total $\left(\mathrm{r}=0,85^{*}\right)$. Hal ini menunjukkan bahwa peningkatan $\mathrm{pH}$ tanah memiliki hubungan yang berbanding lurus dengan Ntotal dan $\mathrm{NO}_{3}$ dalam tanah. Kyveryga et al. (2004), menyatakan bahwa pH tanah merupakan faktor penting yang mempengaruhi 


\section{Jurnal Tanah dan Sumberdaya Lahan Vol 6 No 2 : 1291-1299, 2019 e-ISSN:2549-9793, doi: 10.21776/ub.jts1.2019.006.2.10}

proses nitrifikasi dalam menghasilkan nitrat dalam tanah. Semakin tinggi nilai $\mathrm{pH}$ tanah, maka semakin tinggi nitrat yang tersedia dalam tanah. Sebaliknya, semakin rendah $\mathrm{pH}$ tanah, maka nitrat yang tersedia juga semakin rendah. $\mathrm{pH}$ memberikan pengaruh sebesar 59,28\% terhadap $\mathrm{NO}_{3}$, sisanya $40,72 \%$ dipengaruhi oleh faktor lain pada 30 HSI. Pada pengamatan 60 HSI, pH memberikan pengaruh sebesar $72 \%$ terhadap $\mathrm{N}$-total dan sisanya $28 \%$ dipengaruhi oleh faktor lain.

C-organik memiliki korelasi kuat dan positif dengan $\mathrm{NO}_{3}{ }^{-}\left(\mathrm{r}=0,63^{*}\right)$, dan P-tersedia $\left(\mathrm{r}=0,78^{*}\right)$ pada pengamatan 30 HSI. Hal ini menunjukkan bahwa peningkatan C-organik memiliki hubungan yang berbanding lurus dengan $\mathrm{NO}_{3}$, dan P-tersedia dalam tanah. Bahan organik memiliki korelasi sangat kuat dan positif dengan P-tersedia $\left(\mathrm{r}=0,86^{*}\right)$ dan berkorelasi kuat dengan $\mathrm{NO}_{3}^{-}\left(\mathrm{r}=0,70^{*}\right)$ pada pengamatan 30 HSI. Hal ini menunjukkan bahwa $\mathrm{BO}$ memiliki hubungan yang berbanding lurus dengan $\mathrm{NO}_{3}$, dan P-tersedia dalam tanah. Hasil dekomposisi bokashi dapat meningkatkan ketersediaan $\mathrm{N}$ dan $\mathrm{P}$ dalam tanah disebabkan adanya aktivitas mikroorganisme dalam tanah yang menggunakan bahan organik sebagai sumber energi yang dapat mempercepat proses dekomposisi dan reaksi lain (Hernandez et al., 2014). C-organik memberikan pengaruh sebesar 61,21\% terhadap P-tersedia.. Sedangkan BO mempengaruhi sebesar 49,14\% terhadap $\mathrm{NO}_{3}$, dan $73,80 \%$ terhadap P-tersedia, sedangkan sisanya sebesar $50,86 \%$ dan $26,20 \%$ dipengaruhi oleh faktor lain.

\section{Kesimpulan}

Aplikasi bokashi meningkatkan $\mathrm{pH}$ dan $\mathrm{C} / \mathrm{N}$ rasio pada 60 HSI (Hari Setelah Inkubasi) dibandingkan kontrol, tetapi tidak berpengaruh nyata terhadap C-organik dan $\mathrm{BO}$ dalam tanah. Aplikasi bokashi meningkatkan P-tersedia pada 60 HSI, serta $\mathrm{N}$-total dan $\mathrm{NO}_{3}$ pada 30 dan 60 HSI dibandingkan kontrol, tetapi tidak berpengaruh nyata terhadap ketersediaan $\mathrm{SO}_{4}{ }^{2-}$.

\section{Daftar Pustaka}

Amijaya, M., Pata'dunga, Y. dan Thaha, A.R. 2015. Pengaruh pupuk kandang sapi terhadap serapan posfor dan hasil tanaman bawang merah (Allium ascalonicum L.) varietas lembah palu di entisol Sidera. E-jurnal Agrotekbis 3 (2) : 187-197.

BALITAN. 2009. Petunjuk Teknis Edisi 2: Analisis Kimia Tanah, Tanaman, Air, dan Pupuk. Balai Penelitian Tanah. Bogor.

Balitsa. 2013. Budidaya Bawang Merah dalam balitsa.litbang.pertanian.go.id/ind/index.php/ber ita-terbaru/171-budidaya-bm.html. Diakses pada tanggal 30 Desember 2017.

Bhaskar, K.V. and Charyulu, P.B.B.N. 2005. Effect of environmental factors on nitrifying bacteria isolated from the rhizosphere of Setaria italica (L.) Beauv. African Journal of Biotechnology 4 (10): 1145-1146.

Boechat, C.L., Santos, J.A.G. and de Accioly, A.M.. 2013. Net mineralization nitrogen and soil chemical changes with application of organic wastes with 'fermented bokashi compost'. Acta Scientiarum Agronomy 35 (2) : 257-264.

Gee, C.S., Preffer, J.T. and Suidan, M.T. 2014. Nitrosomonas dan Nitrobacter interactions in biological nitrification. Journal of Environmental Engineering 1 (4): 4-17.

Hernandez, M.I.S., Alvarez, R.G., M.del Cruz, C.R., Solis, J.D.A., Fernandez, J.M.P. and Garcia, C.F.O. 2014. The Influence of organic fertilizers on the chemical properties of soil and the production of Alpinia purpurata. Ciencia e Investigación Agraria 41 (2) : 215-224.

Irawan, H.S. 2012. Teknik Pembuatan Pupuk Bokashi. Jakarta: DANIDA. pp.8-13.

Kaya, E. 2012. Pengaruh pemberian bokashi ela sagu dan pupuk ABG bunga-buah terhadap Ntersedia, serapan-N, serta hasil tanaman jagung (Zea mays L.) pada Inceptisol. Jurnal Budidaya Pertanian 8 (2) : 89-94.

Kusuma, M.E. 2012. Pengaruh beberapa jenis pupuk kandang terhadap kualitas bokashi. Jurnal Ilmu Hewani Tropika 1 (2) : 41-46.

Kyveryga, P.M., Blackmer, A.M., Ellsworth, J.W. and Isla, R. 2004. Soil pH effects on nitrification of fall-applied anhydrous ammonia. Soil Science Society of America Journal 68 : 545-551.

Muyassir, Sufardi, dan I. Saputra. 2012. Perubahan sifat fisika inceptisol akibat perbedaan jenis dan dosis pupuk organik. Jurnal Lentera 12 (1) : 1-8.

Sari, M.N., Sudarsono, dan Darmawan. 2017. Pengaruh bahan organik terhadap ketersediaan fosfor pada tanah-tanah kaya $\mathrm{Al}$ dan $\mathrm{Fe}$. Buletin Tanah dari Lahan 1(1) : 65-71.

Solis, J.D.A., Nunez, J.A.M., Martinez, N.S.L. Albores, J.C. and Miceli, F.A.G. 2016. Effect of bokashi and vermicompost leachate on yield and quality of pepper (Capsicum annumm) and onion (Allium cepa) under monoculture and intercropping cultures. Ciencia E-Investigacion Agraria 43 (2) : 243-252. 
Suriadikarta, D.A. dan Setyorini, D. 2016. Pupuk Organik dan Pupuk Hayati. Balai Besar Litbang Sumberdaya Lahan Pertanian Badan Penelitian dan Pengembangan Pertanian. Bogor.

Velasco, D.A.G., Solis, J.D.A., Valdiviezo, V.M.R., Archila, M.A., Molina, J.A.M., Miguel, A., Joaquin, A., Montes-Molina, L. Dendooven, and Miceli, F.A.G. 2014. Enzymatic activities in soil cultivated with coffee (Coffea arabica L. cv. 'Bourbon') and amended with organic material. Communications in Soil Science and Plant Analysis $45: 2529-2538$.
Wijayanto, Zulfikar, T., Tufaila, M., Sarman, A.M. and Zamrun, M. 2016. Influence of bokashi on soil chemical properties, soybean (Glycine max (L.) Merrill) yield compnents and production. WSEAS Transactions on Biology and Biomedicine $13: 134-141$.

Yuliana, A.I., Sumarni, T. and Islami, T. 2015 Application of bokashi and sunn hemp (Crotalaria juncea L.) to improve inorganic fertilizer efficiency on maize (Zea mays L.). Journal of Degraded and Mining Lands Mangement 3 (1) : 433-438. 